\title{
Predictors of Quality of Life Quality of Adults with Coronary Artery Disease (CAD)
}

\author{
Zuriati Zuriati $^{1}$, Farida Moh. Said ${ }^{2}$, Milya Novera ${ }^{3}$ \\ ${ }^{1,2}$ Student of Lincoln University Malaysia, ${ }^{2}$ Lincoln University Malaysia, ${ }^{3}$ STIKes YPAK Padang
}

\begin{tabular}{|c|c|}
\hline ARTICLE INFO & ABSTRACT \\
\hline Article history: & $\begin{array}{l}\text { Quality of Life is as a predictor of general wellbeing that is an important } \\
\text { outcome in the treatment of any chronic disease. Impaired quality of life has }\end{array}$ \\
\hline DOI: & increasingly become the most significant health outcome for CAD patients \\
\hline $10.30595 / \mathrm{pshms} . v 2 \mathrm{i} .247$ & $\begin{array}{l}\text { The purpose of this study was to identify the predictor of quality of life of } \\
\text { adults with CAD Patients. A descriptive cross-sectional study was conducted }\end{array}$ \\
\hline & with sample of 125 participants of age between 35 to 64 years from RSUP. \\
\hline $\begin{array}{l}\text { Submitted: } \\
\text { December 6, } 2021\end{array}$ & $\begin{array}{l}\text { Dr. M. Djamil Hospital, Padang, West Sumatera, Indonesia. Each participant } \\
\text { was administrated structured questionnaires, including the socio- } \\
\text { demographic questionnaire, the CADE-Q questionnaire, Social Support }\end{array}$ \\
\hline Accepted: & questionnaire, general health perception, and the World Health Organization \\
\hline January 21,2022 & Quality of Life-BREF (WHOQOL-BREF). A regression model showed that \\
\hline $\begin{array}{l}\text { Published: } \\
\text { January 26, } 2022\end{array}$ & $\begin{array}{l}\text { Income, Duration of CAD, and general health perception were the predictors } \\
\text { of patient's quality of life (Adjusted R2 }=.031, \mathrm{p}<.01 \text { ). Better } \\
\text { understanding of the relationship between its predictor and quality of life is } \\
\text { necessary to develop a suitable nursing intervention program to enhance }\end{array}$ \\
\hline
\end{tabular}

Keywords:

Self-efficacy; Motivation; elderly's daily independence; Elderly Social Service

This work is licensed under a Creative Commons Attribution 4.0 International License.

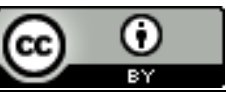

Corresponding Author:

Zuriati,

Student of Lincoln University Malaysia

Email: zuriati3781@gmail.com

\section{INTRODUCTION}

Coronary artery disease (CAD) is the common term to explain for the build-up of plaque in the heart's arteries that could lead to a heart attack. The build-up of plaque within the wall of the coronary arteries limit, decrease and sometimes completely cut off the supply of oxygen and nutrients to the heart muscle [1]. Coronary Heart Disease is the most common type of heart disease, killing 365,914 people in 2017 [2]. About 17.7 million people died from Cardiovascular Disease worldwide, representing $31 \%$ of all global deaths; out of whom, 7.4 million were due to $\mathrm{CAD}$, and 6.7 million were due to stroke [3]. It account about 2 in 10 deaths from CAD happen in adults less than 65 years old [2]. Thus, it has become the heaviest burden to health care systems worldwide [4].

Meanwhile, although among cardiovascular disease, coronary artery disease is one of the most important death causes in the United States, it is estimated that 80 percent of the premature deaths due to this disease can be prevented [5]. Mortality rate and reinfection are considered major adverse clinical outcome. On the other hand, expression of clinical signs and symptoms, functional ability, the wellbeing of the patient and their quality of life are important outcomes in survivors. Health-related quality of life (HRQoL) represents the effects of an illness and its treatment as perceived by the patient [6].

The South-East Asia region, premature death from non-communicable diseases (NCD), primarily from cardiovascular disease of the 7.9 million annual NCD, 34\% occur before the age of 60 years compared 
with $16 \%$ in the European region and $23 \%$ in the rest of the world [7]. This in line with data indicate half of the world's cardiovascular burden is estimated to occur in Asia [8], and the prevalence of symptomatic heart failure appears to be higher in South East Asia countries compared with the rest of the world [9]. Despite the high burden of cardiovascular disease in South-East Asia, little is known about characteristics at admission and clinical outcomes in patients with coronary artery disease, especially acute coronary syndrome [10].

Coronary Artery Disease is the second leading cause of death in Indonesia, in 2012 representing 9\% of deaths $(138,400$ people) [4]. Approximately one-third of mortality in Indonesia can be attributed to cardiovascular diseases (Alkatiri et al., 2020). The prevalence of coronary heart disease (based on diagnosis) in Indonesia was $1.5 \%$ (1.017.290 patients) in the year 2018 (Ministry of Health RI, 2018). Due to the increasing incidence of coronary artery disease in recent years, interventions targeting coronary artery disease risk factors are urgent public priorities.

Quality of life measures are useful when interventions or treatments are indicated for several reasons such as improvement of physical functioning, pain relief, to estimate the effectiveness of therapies and to predict mortality [11]. Impaired quality of life has increasingly become the most significant health outcome for patients with chronic diseases such as coronary artery disease (CAD). Outcomes of treatment of any chronic disease are not merely predicted by the frequency and severity of the disease, but also how this treatment will affect the patient's QoL and general wellbeing.

Coronary artery disease is a major cause of death and morbidity as well as impaired quality of life [12]. In modern medicine, QoL is as a predictor of general wellbeing that is an important outcome in the treatment of any chronic disease [13]. The main risk factors for CAD - obesity and sedentary lifestyle coupled with high blood pressure, smoking and high blood cholesterol are amenable to behavioural change interventions [14]. Medication adherence presents a particular challenge as non-adherence in Cardiovascular Disease patients is associated with poor self-management leading to poor clinical outcomes, including rehospitalization, subsequent myocardial infarction and increased mortality [15]. Therefore, there is a need for an educational strategy for CAD patients to help them stay fit through therapeutic lifestyle changes and a need for consistent research on the effects of individualized educational interventions. The purpose of this study was to identify the predictor of quality of life of adults with CAD Patients.

\section{RESEARCH METHOD}

This study will use a quantitative study, carried out in January to April 2021. A descriptive crosssectional study was conducted with sample of 125 participants of age between 35 to 64 years from RSUP. Dr. M. Djamil Hospital Indonesia. Each participant was administrated structured questionnaires, including the socio-demographic questionnaire, the CADE-Q questionnaire, Social Support questionnaire, general health perception, and the World Health Organization Quality of Life-BREF (WHOQOL-BREF). The hypotheses will then test according to their statistical properties. Descriptive statistics and regression model was calculated to determine the hypotheses of the study.

\section{RESULT AND DISCUSSIONS}

\section{Predictors of quality of life of Patients with CAD}

1. Multiple linear regression analysis of predicting variables on overall quality of life of patient with CAD

\begin{tabular}{|c|c|c|c|c|c|}
\hline Variables & B & $\mathrm{SE}$ & $\beta^{*}$ & $\mathrm{t}$ & $\begin{array}{l}\mathrm{P}- \\
\text { value }\end{array}$ \\
\hline Constant & 62.939 & 3.747 & & 16.789 & 0.000 \\
\hline Age & -0.103 & 0.648 & $-\overline{0.016}$ & -0.159 & 0.874 \\
\hline Gender & 0.983 & 1.006 & 0.093 & 0.977 & 0.331 \\
\hline Income & 0.285 & 0.846 & 0.038 & 0.337 & 0.737 \\
\hline Education & 0.841 & 0.785 & 0.118 & 1.070 & 0.287 \\
\hline Occupation & 0.922 & 1.789 & $-\overline{0}$ & -0.515 & 0.607 \\
\hline $\begin{array}{l}\text { Social } \\
\text { support }\end{array}$ & -0.415 & 1.124 & $-\overline{0}$ & -0.370 & 0.712 \\
\hline $\begin{array}{l}\text { Body Mass } \\
\text { Index }\end{array}$ & 0.042 & 0.676 & 0.006 & 0.063 & 0.950 \\
\hline $\begin{array}{l}\text { Duration } \\
\text { of CAD }\end{array}$ & 0.680 & 1.308 & 0.053 & 0.520 & 0.604 \\
\hline General & -2.200 & 1.731 & - & -1.127 & 0.206 \\
\hline
\end{tabular}




$$
\begin{aligned}
& \text { health } \\
& \text { perception } \\
& \mathrm{R}=.175 \\
& \mathrm{R}^{2}=.0 .031 \\
& \text { Adjusted } \mathrm{R}^{2}=.-0.036 \\
& \mathrm{~F}=0.460(0.882)
\end{aligned}
$$

2. Multiple linear regression analysis of predicting variables on physical domain of quality of life of patient with CAD Patients

\begin{tabular}{lccccc}
\hline Variables & $\mathrm{B}$ & SE & $\beta^{*}$ & $\mathrm{t}$ & $\begin{array}{c}\mathrm{P}- \\
\text { value }\end{array}$ \\
\hline Constant & 5.929 & 1.826 & & 3.247 & .001 \\
Age & -.020 & .016 & - & - & .210 \\
& & & .065 & 1.260 & \\
Gender & .066 & .254 & .013 & .259 & .796 \\
Income & 2.758 & .000 & .146 & 2.306 & .022 \\
Education & -.003 & .030 & - & -.102 & .919 \\
Occupation & .537 & .324 & .104 & 1.660 & .099 \\
$\begin{array}{l}\text { Social } \\
\text { support }\end{array}$ & .003 & .021 & .006 & .119 & .906 \\
$\begin{array}{l}\text { Body Mass } \\
\text { Index }\end{array}$ & .070 & .035 & .096 & 1.966 & .051 \\
$\begin{array}{l}\text { Duration } \\
\text { of CAD }\end{array}$ & -.050 & .029 & - & - & .086 \\
$\begin{array}{l}\text { General } \\
\text { health }\end{array}$ & .657 & .119 & .394 & 5.538 & .000 \\
perception & & & & & \\
\hline
\end{tabular}

3. Multiple linear regression analysis of predicting variables on psychological domain of quality of life of patient with CAD.

\begin{tabular}{lccccc}
\hline Variables & $\mathrm{B}$ & $\mathrm{SE}$ & $\beta^{*}$ & $\mathrm{t}$ & $\begin{array}{c}\mathrm{P}- \\
\text { valu } \\
\mathrm{e}\end{array}$ \\
\hline Constant & 7.377 & 1.824 & & 4.045 & .000 \\
Age & - & .016 & .000 & -.003 & .998 \\
& 4.16 & & & & \\
Gender & 3 & & & & \\
& -.069 & .254 & - & -.270 & .787 \\
Income & 2.995 & .000 & .172 & 2.507 & .013 \\
Education & .009 & .030 & .018 & .303 & .762 \\
Occupation & .447 & .323 & .093 & 1.382 & .169 \\
Social & .031 & .021 & .081 & 1.444 & .151 \\
support & & & & & \\
Body Mass & .026 & .035 & .038 & .726 & .469 \\
Index & & & & & \\
Duration & -.045 & .029 & - & - & .118 \\
of CAD & & & .08 & 1.57 & \\
CADEQ & -.105 & .030 & - & - & .001 \\
& & & .25 & 3.52 & \\
General & .614 & .118 & .400 & 5.182 & .000 \\
\hline
\end{tabular}


health

perception

4. Multiple linear regression analysis of predicting variables on social domain of quality of life of patient with CAD.

\begin{tabular}{lccccc}
\hline Variables & $\mathrm{B}$ & $\mathrm{SE}$ & $\beta^{*}$ & $\mathrm{t}$ & $\begin{array}{c}\mathrm{P}- \\
\text { value }\end{array}$ \\
\hline Constant & 7.948 & 1.823 & & 4.360 & .000 \\
Age & -.020 & .016 & - & - & .203 \\
& & & .082 & 1.278 & \\
Gender & .327 & .253 & .080 & 1.291 & .198 \\
Income & 2.808 & .000 & .184 & 2.352 & .020 \\
Education & .023 & .030 & .054 & .791 & .430 \\
$\begin{array}{l}\text { Occupation } \\
\text { Social }\end{array}$ & .115 & .323 & .028 & .357 & .722 \\
$\begin{array}{l}\text { support } \\
\text { Body Mass }\end{array}$ & .026 & .021 & .073 & 1.143 & .255 \\
$\begin{array}{l}\text { Index } \\
\text { Duration } \\
\text { of CAD }\end{array}$ & -.061 & .029 & - & - & .035 \\
$\begin{array}{l}\text { General } \\
\text { health }\end{array}$ & .430 & .118 & .320 & 3.629 & .000 \\
perception & & & & & \\
\hline
\end{tabular}

5. Multiple linear regression analysis of predicting variables on environment domain of quality of life of patient with CAD.

\begin{tabular}{llllll}
\hline Variables & $\mathrm{B}$ & $\mathrm{SE}$ & $\beta^{*}$ & $\mathrm{t}$ & $\begin{array}{l}\text { P- } \\
\text { valu } \\
\mathrm{e}\end{array}$ \\
\hline Constant & 2.668 & 2.011 & & 1.327 & .186 \\
Age & .029 & .017 & .111 & 1.634 & .104 \\
Gender & .029 & .280 & .007 & .105 & .917 \\
Income & 2.992 & .000 & .189 & 2.271 & .024 \\
$\begin{array}{l}\text { Education } \\
\text { Occupation }\end{array}$ & .052 & .033 & .115 & 1.596 & .112 \\
$\begin{array}{l}\text { Social } \\
\text { support }\end{array}$ & .033 & .356 & .032 & .387 & .700 \\
$\begin{array}{l}\text { Body Mass } \\
\text { Index }\end{array}$ & .060 & .039 & .095 & 1.393 & .165 \\
$\begin{array}{l}\text { Duration } \\
\text { of CAD }\end{array}$ & -.011 & .032 & - & -.351 & .726 \\
& & & .02 & & \\
$\begin{array}{l}\text { sGeneral } \\
\text { health } \\
\text { perception }\end{array}$ & .457 & .131 & .328 & 3.501 & .001 \\
\hline
\end{tabular}

Correlation coefficients between independent variables with overall quality of life, and in all four domain of quality life of patient with CAD

\begin{tabular}{|c|c|c|c|c|c|}
\hline \multirow[b]{2}{*}{ Variables } & \multicolumn{5}{|c|}{ QUALITY OF LIFE } \\
\hline & $\begin{array}{c}\text { Overall } \\
\text { QOL }\end{array}$ & PQOL & $\begin{array}{l}\text { Psyc } \\
\text { QOL }\end{array}$ & SQOL & EQOL \\
\hline Age & 0.053 & 0.008 & -0.405 & 0.002 & 0.038 \\
\hline Gender & 0.072 & 0.134 & 0.075 & -0.193 & 0.001 \\
\hline Income & 0.049 & 0.013 & 0.060 & 0.079 & 0.043 \\
\hline
\end{tabular}




\begin{tabular}{llllll}
\hline Education & 0.021 & 0.066 & 0.052 & 0.088 & 0.073 \\
Occupation & -0.039 & -0.044 & 0.103 & 0.048 & -0.100 \\
Social Support & -0.012 & 0.052 & -0.051 & -0.074 & -0.070 \\
BMI & -0.012 & -0.027 & -0.003 & -0.087 & 0.078 \\
Duration of & 0.063 & 0.027 & 0.040 & -0.015 & -0.043 \\
CAD & & & & & \\
CADEQ & 0.111 & -0.141 & 0.111 & 0.089 & 0.057 \\
GHP & -0.145 & -0.018 & 0.005 & -0.185 & -0.078.
\end{tabular}

Our study revealed that gender was not statistically significant relationship with overall quality of life, physical, and psychological domains of quality of life. On the contrary, age and social support were small but statistically significant positive relationship with overall quality of life, and all four domains of quality of life $(\mathrm{p}<0.01)$.

Moreover, people with better social support would receive more resources to promote their quality of life. This study was consistent with previous studies of quality of life of CAD patients by Huang and Hung, (2007), and Huang et al. (2010) which found that social support had a significant direct effect on quality of life. Perceived social support and quality of life were increased together. This result concurs with other studies that show social support is negatively correlated with readmission. For example, social support has been shown to be related to decrease readmission and mortality rates among CAD patients (Lu et al., 2016) and Najafi et al. also reported that male sex was an independent physical component predictor of higher QOL.

In contrast, Nesbitt et al. argued that male sex was associated with lower QOL and that the sex difference was due to differences in family responsibility and gender roles and the responsibility of looking after one's own health. Age and sex were predictors of MCS QOL. Hawkes et al. listed younger age as a predictor and McBurney et al. found age below 65 years to be associated with low MCS-12 scores. Other study explained that these conditions were possible when older adults lowering their expectations about what constitutes a good quality of life as compared to younger people. However, being older are more accustomed to the limited functioning and view declining physical abilities as part of the normal aging process. [10]

For environment variable, education had positively significant relationship with overall quality of life and psychological domains of quality of life. Regarding income, there was positively significant relationship between income and overall quality of life, physical and environment domains of quality of life. Occupation had positively significant relationship with subjective quality of life and all three domains of quality of life except psychological domain of quality of life. Social support had positively significant relationship with overall quality of life and all four domains of quality of life. This indicated that the participants with higher level of education were more likely to have better quality of life. One possible explanation, when exposed to same information pertaining to participants with higher level of education may have positive self-esteem, a better understanding of the disease, treatment, and complication rather than participants with lower level of education. [11]

Regarding income, there was positively significant relationship between income and overall quality of life, physical and environment domains of quality of life. This indicated that the lower income may lead to lowering the quality of life. One reason for this finding was probably over half of the participants in this study were in the lowest socio-economic level. When the participants did not have enough money to afford the daily expenses, they might be unsatisfied with their life, resulting in poorer quality of life. This result was consistent with previous studies. [12]

The result were completely different from the study conducted by Htet, (2009) showed that participants with higher income were more likely to have lower quality of life than those who have lower income.

Occupation had positively significant relationship with subjective quality of life and all three domains of quality of life except psychological domain of quality of life. This indicated that the employed participants were more likely to have higher quality of life than those who were unemployed. This result was consistent with a previous study by Papadopoulos et al. (2007) showed that employed participants were more likely to have lower quality of life than those who were unemployed. These because of the majority of the participants were unemployed.

The relationship between biological and physiological factors and quality of life were examined. The biological and physiological factors variables examined were BMI, and duration of CAD. As shown in Table above, there was statistically significant relationship between overall quality of life, and all three domains of quality of life except environment domain of quality of life with BMI ( $\mathrm{p}=0.078, \mathrm{p}>0.05)$. 
Furthermore, duration of CAD was negative statistically significant relationship with overall Qol $(p=0.063$, $\mathrm{p}>0.05)$. The level of knowledge and educate coronary patients was negatively statistical significant relationship with social $(\mathrm{p}=0.089, \mathrm{p}>0.05)$, overall quality of $(\mathrm{p}=0.111, \mathrm{p}>0.05)$ and psychological domain of quality of life $(\mathrm{p}=0.111, \mathrm{p}>0.05)$. General health perception had positively statistical significant relationship with overall quality of life $(\mathrm{p}<0.01)$ and all four domains of quality of life $(\mathrm{p}<0.01)$.

According to Wilson and Cleary's model for health related quality of life (Ferrans et al., 2005), biological and psychological factors are the most basic determinant of quality of life focusing on the function of cells, organs, and organ systems. For biological and psychological factors, there was statistically significant relationship between overall quality of life, and all three domains of quality of life except environment domain of quality of life with BMI.

Duration of CAD was negative statistically significant relationship with overall Quality of Life. This result indicated that the negative effect caused by the CAD duration on energy and general health of the patients as well as on social functioning of quality of life. On the other words, patients with relatively longer CAD duration could lead to impaired lowering quality of life. The possible reason was since the patients had been diagnosed with cardiovascular disease, which could not be completely cured and required long-term control. As complications developed, new symptoms emerge and a variety of treatments tends to be more complex. The longer patients have the illness, the worse they feel [9].

\section{CONCLUSION}

Predictors of quality of life of CAD included general health, income, level of knowledge about CAD could explain of the variance in domain physical and psychological quality of life. Income, duration of CAD, and general health perception could explain of the variance in domain social quality of life. Income and general health perception could explain of the variance in domain environment domain of quality of life. Income, Duration of $\mathrm{CAD}$, and general health perception appears to be an important variable determining quality of life. There were some limitations in this study that could influence the generalizability of findings. Better understanding of the relationship between its predictor and quality of life is necessary to develop a suitable nursing intervention program to enhance patient's quality of life. These finding provided essential information in monitoring the quality of life of patients with CAD. Knowing the quality of life, as well as factors that influence it, could be assisted health care provider in developing suitable interventions by targeting the predictors to promote these individual's quality of life, as well as informing resource allocation and healthcare policy.

\section{Acknowledgements}

Thank you to Allah SWT, both parents and all comrades in arms who have helped from beginning to end.

\section{REFERENCES}

[1] Sanchis-Gomar, F., et al., "Epidemiology of coronary heart disease and acute coronary syndrome. Annals of translational medicine," 2016.

[2] Benjamin EJ, M.P., Alonso A, Bittencourt MS, Callaway CW, Carson AP, et al, "Heart disease and stroke statistics update: a report from the American Heart Association Circulation," 2019;139(10):e56-5282019.

[3] Jamee Shahwan, A., et al., "Epidemiology of coronary artery disease and stroke and associated risk factors in Gaza community-Palestine," PloS one, 2019. 14(1): p. e0211131.

[4] WHO, "World Health Organization (WHO); Media centre: cardiovascular diseases (CVDs)," 2015; Available from: http://www. who. int/ mediacentre/ factsheets/ fs317/ en/.

[5] Abbasi, S., et al., "Designing and manufacturing of educational multimedia software for preventing coronary artery disease and-its effects on modifying the risk factors in patients with coronary artery disease," Electronic Journal of General Medicine, 2018. 15(3).

[6] Staniute, M., J. Brozaitiene, and R. Bunevicius, "Effects of social support and stressful life events on health-related quality of life in coronary artery disease patients," Journal of Cardiovascular Nursing, 2013. 28(1): p. 83-89.

[7] WHO, "World Health Organization (WHO); Health Education: Theoretical Concepts, in Effective Strategies and Core Competencies: A Foundation Document to Guide Capacity Development of Health Educators," 2012.

[8] Ohira, T. and H. Iso, "Cardiovascular disease epidemiology in Asia," Circulation Journal, 2013: p. CJ-13-0702.

[9] Lam, C.S., "Heart failure in Southeast Asia: facts and numbers," ESC heart failure, 2015. 2(2): p. 46-49. 
[10] Qanitha, A., et al., "Characteristics and the average 30-day and 6-month clinical outcomes of patients hospitalised with coronary artery disease in a poor South-East Asian setting: the first cohort from Makassar Cardiac Center, Indonesia," BMJ open, 2018. 8(6): p. e021996.

[11] Moryś, J.M., et al., "Quality of life in patients with coronary heart disease after myocardial infarction and with ischemic heart failure,"Archives of medical science: AMS, 2016. 12(2): p. 326.

[12] Le, J., et al., "Health-related quality of life in coronary heart disease: a systematic review and metaanalysis mapped against the international classification of functioning, disability and health. Quality of Life Research, 2018. 27(10): p. 2491-2503.

[13] Barham, A., R. Ibraheem, and H.Z. Sa'ed, "Cardiac self-efficacy and quality of life in patients with coronary heart disease: a cross-sectional study from Palestine, " BMC Cardiovascular Disorders, 2019. 19(1): p. 290.

[14] Coorey, G.M., et al., "Effectiveness, acceptability and usefulness of mobile applications for cardiovascular disease self-management: Systematic review with meta-synthesis of quantitative and qualitative data," European journal of preventive cardiology, 2018. 25(5): p. 505-521.

[15] Du, L., et al., "The impact of medication adherence on clinical outcomes of coronary artery disease: A meta-analysis," European journal of preventive cardiology, 2017. 24(9): p. 962-970. 